International forum

\section{International Forum in Health Care, 2007}

\section{P Stevens}

\section{Launch of a new international forum in Barcelona, 2007}

$\mathrm{T}$ here is a remarkable story about an avid, amateur sailor who sailed the lakes of northern Michigan in the US from spring to autumn, for decades. Each winter he would spend the cold months in his workshop building a new boat. Every year, just as the sailing season wound down, he would invite his friends to an outdoor party on the shores of Lake Michigan. The featured event would be the destruction of the boat he had sailed that year. He would burn it to the ground, in a dramatic bonfire. The next day he would set about designing a new boat for the next season, incorporating all the best characteristics of his earlier models, plus new improvements gleaned from his experience and research.

New attendees at these lakeside events were frequently startled by the seeming violence of the event. They asked how this keen life-long sailor could destroy a boat that had served him so well. His response seemed rooted in a Zen-like relationship with his boat. He explained that he was not attached to any particular boat, so much as he strived for an ideal, a quest for the best possible boat.

In Barcelona in 2007, the BMJ Publishing Group and the Institute for Healthcare Improvement will launch a new forum, the International Forum on Quality and Safety. There is more to this than changing the name of the former European Forum. An international strategic advisory board of scholars, improvement experts, and health professionals has been working with BMJ Publishing Group staff to build on the best of previous forums, while selectively adding new innovations (see end of editorial for list of advisory board members). The forum will incorporate ideas from focus groups and extensive attendee surveys. Following three faceto-face meetings-one in Prague and two in London-and with the aid of monthly international conference calls, the advisory board strived to craft a lively, innovative, educational and truly international forum.

This year's forum will endeavour to showcase the strategies, innovation and ideas that reside in our global quality improvement and safety community. It will present the diversity of work that is found throughout the world—strategies that frequently take different forms in dissimilar national settings and local health systems. It will also highlight improvement work that has been accomplished in the host country.

Many previous components will be preserved. There will be an extensive poster session with awards for the best presentation, including commissioned publication in QSHC. Again, all attendees will receive a year's subscription to $Q S H C$. Plenary sessions, mini-courses and workshops will be retained, with presentations by the many improvement experts that continue to move the field forward.

But the Forum will also offer innovations and new voices that have not been heard before. Nearly three times as many proposals were received for the 2007 Forum compared with 2006. There will be fewer full-day mini-courses and more half-day mini-courses, to allow presenters and attendees to pursue broader opportunities for indepth interactions. An emphasis will be placed on the pace of presentations. The plenary presentations will be shortened to allow for more interaction with the audience. One plenary will be a debate, and another will feature a panel. Improvement experts from outside healthcare will be invited to provide a broader perspective. Attendees will be provided with opportunities to pursue topics in depth after the sessions, with more effective use of the forum website for dissemination of knowledge resources and references. Workshop presentations will vary in length, with ample time for discussion and emphasis on interactive learning. There will also be an effort to make registration simpler and participation easier.

Finally, there will be more extensive time for networking among attendees. This will include more social events, but no bonfires. However, be assured that as the meeting concludes, the planning will begin yet again for an even better event in 2008.

Qual Saf Health Care 2006;15:386. doi: 10.1136/qshc.2006.021337

Correspondence to: Dr David P Stevens, Institute for Improving Clinical Care, Association of American Medical Colleges, 2450 N Street, NW, Washington, DC 20037, USA; dstevens@aamc.org

Competing interests: Dr Stevens is the editor of one of the BMJ Journals (Quality and Safety in Healthcare) and is a former George W Merck Senior Fellow, Institute for Healthcare Improvement.

Strategic planning committee: Marchella Mitchell (UK), Rachel Naish (UK), Jane Smith (UK), Rosa Suñol (Spain), David Stevens (US), Ross Wilson (Australia), Penny Carver (US), Göran Henriks (Sweden), Helen Bevan (UK), Piera Poletti (Italy), Wim Schellekens (The Netherlands), Alex Williamson (UK), Mats Bojestig (Sweden). 